\title{
Temporary warehouses for an earthquake in San Borja and San Luis, Lima, Peru
}

\author{
Renzo Benavente, Industrial Engineer ${ }^{1}$, Jonatan Rojas, Industrial Engineer ${ }^{2}$ \\ ${ }^{1}$ Pontificia Universidad Católica del Perú, Perú, renzo.benavente@pucp.pe \\ ${ }^{2}$ Pontifica Universidad Católica del Perú, Perú, jrojasp@pucp.pe
}

\begin{abstract}
A critical scenario of a magnitude 8.0 Mw earthquake is presented with epicenter in Lima, after which it is necessary to distribute humanitarian aid to 4,626 victims in San Borja and San Luis. The scenario works under the assumption that the affected population will have to approach the selected park in order to receive aid goods. The proposal is divided into two parts: the first is responsible for locating the temporary warehouses with the $k$ means algorithm and then determining the optimal distribution route starting from the selected warehouses.

Keywords-- Humanitarian logistics, vehicle routing problem, earthquakes.
\end{abstract}

\section{INTRODUCTION}

Peru is one of the countries that are located in the Pacific Ring of Fire and this explains why in the last three years more than 200 earthquakes have been registered per year [1]. The surface of Metropolitan Lima represents $0.22 \%$ of the Peruvian territory; however, it concentrates $32 \%$ of the national population. It is located on the coast of the country, and on the western slope of the Andes, facing the Pacific Ocean. The Peruvian capital has been shaken by destructive earthquakes in 1908, 1932, 1940, 1966 and 1974, whose magnitudes vary between 7 and 8.2 on the Richter scale [2].

There is a "seismic silence" since 1974 which indicates that underground energy has been accumulating, which could be released at any time through a large earthquake of 8.0 Richter or higher. The purpose of non-food humanitarian aid is to temporarily replace a damaged dwelling by providing the family with a tent, shelter, kitchen utensils, etc. These assets must be provided free of charge and immediately to the affected population during the first 72 hours of a disaster [3].

This document seeks to determine where to locate temporary warehouses and which would be the convenient routes for the distribution of humanitarian aid to the affected population of San Borja and San Luis after the occurrence of an earthquake of $8 \mathrm{Mw}$ in the Peruvian capital.

\section{STATE OF THE ART}

\section{A. Warehouse location}

The location of warehouses seeks to obtain the best location for the implementation of a warehouse taking into account variables such as the number of demanding points, the distance between these and the possible location of the warehouse.

In general, there are several strategies to determine the location of a warehouse, such as a center of gravity approach to locate a single warehouse considering distances between nodes [4]. A variation of this strategy, for cases in which you want to locate more than one depot, is the k-means method. This clustering methodology divides a group of clients into $\mathrm{k}$ groups and the store would be located in the center of gravity of each group [5].

\section{B. Vehicle routing}

Vehicle routing problem, VRP, refers to any problem related to the distribution of goods between depots and customers. It seeks to determine a group of routes, each executed by a single vehicle that initiates and ends the route in a warehouse, such that all customers are served, the operational restrictions met and the overall cost minimized [6].

The first to give a real application to the VRP sought to optimize the routing of a fleet of gas distribution trucks to a large number of service stations, starting from a central warehouse. In this case, the vertices represent the depot and each of the service stations that must be supplied, while the arcs represent the distance between each of these nodes [7].

Generally, this problem is described in a graph whose arcs represent paths and the vertices indicate the location of the depot and the clients. Each client has a requirement of goods, which must be distributed by a fleet of vehicles, whose quantity and load capacity are parameters of the problem. Each arc is associated with a cost, which usually represents the distance between nodes, or the time it takes to move from one point to another. Below is the VRP model proposed in reference [8] which is based on a complete graph defined by $G=(V, A)$, where $\mathrm{V}=(0,1,2, \ldots, \mathrm{n})$ is the set of vertices and $\mathrm{A}$ is the set of possible arcs. The vertices $\mathrm{i}=1,2, \ldots, \mathrm{n}$ correspond to the clients, which in turn belong to the subset $\mathrm{N}$; while vertex 0 corresponds to the depot.

$$
\begin{array}{ll}
\text { Min } \sum_{i \in V} \sum_{j \in \mathrm{V}} C_{i j} x_{i j} & \\
\text { Subject to: } & \\
\sum_{j \in V} x_{i j}=1 & \forall i \in N \\
\sum_{i \in V} x_{i j}=1 & \forall j \in N \\
\sum_{i \in V} x_{i 0}=|K| & \forall S \subseteq N, S \neq \emptyset \\
\sum_{i \notin S} \sum_{j \in \mathrm{S}} x_{i j} \geq r(S) & \forall i, j \in V \\
x_{i j} \in\{0,1\} &
\end{array}
$$

It should be noted that $\mathrm{x}_{\mathrm{ij}}$ is a binary variable that is worth 1 when a vehicle circulates through the arc $(i, j)$, or otherwise zero. The objective function shown in (1) represents the total cost of the route, and the model will look for the lowest possible amount. The restriction (2) indicates that each customer must be served only by a vehicle and also guarantees that all customers are served, while the restriction (3) requires that the

Digital Object Identifier (DOI): http://dx.doi.org/10.18687/LACCEI2018.1.1.172 ISBN: 978-0-9993443-1-6 ISSN: $2414-6390$

16 $^{\text {th }}$ LACCEI International Multi-Conference for Engineering, Education, and Technology: "Innovation in Education and Inclusion", 19-21 July 2018, Lima, Peru. 
vehicle must depart from that customer and continue with their route. The restriction (4) indicates that a number $\mathrm{K}$ of vehicles start from the depot and that this same amount must return by ending their routes. The restriction (5) imposes the load capacity requirements for each route. Finally, restriction (6) defines the model as a binary integer.

A special case is when you only have a non-limiting capacity vehicle and only one route is made. This model is called TSP or traveling agent problem (for its acronym in English Traveling Salesman Problem) that can be described as a VRP in which only one vehicle is available. In the reference [9] a mixed whole linear programming model shown below is proposed:

$$
\begin{array}{ll}
\operatorname{Min} \sum_{i \in V} \sum_{j \in \mathrm{V}} C_{i j} x_{i j} & i \neq j \\
\text { Subject to: } & \forall i \in N \\
\sum_{j \in \Delta^{+}(\mathrm{i})} x_{i j}=1 & \forall j \in N \\
\sum_{i \in \Delta^{-}(\mathrm{j})} x_{i j}=1 & 1 \leq i \neq j \leq n \\
u_{i}-u_{j}+n x_{i j} \leq n-1 & \forall i, j \in V \\
x_{i j} \in\{0,1\} & \forall i \in N \\
u_{i} \in \mathbb{Z} &
\end{array}
$$

Where $\mathrm{N}$ is the set of clients to visit, it does not include the deposit, while $\mathrm{V}$ is the set $\mathrm{N} \mathrm{U}\{0\}$. The restrictions (8) and (9) indicate to the model that all customers are visited once and the restriction (10) is responsible for ensuring that no subtitles are generated. The variable ui represents the accumulated number of clients that you have already visited when starting from node i. In other words, if the vehicle goes from node $\mathrm{i}$ to node $\mathrm{j}$, $\mathrm{xij}=$ 1 , the restriction ui $-u j=-1$ must be fulfilled. Otherwise, it must always be fulfilled that $u i-u j=n-1$, where $n$ is the number of clients visited on the route.

\section{APPLICATION OF THE MODEL}

\section{A. Critical scenario}

To determine the critical scenario, the study made by reference [10] was used as the basis, which indicates the maximum magnitude of the probable earthquake, as well as the micro-zonification study which indicates the degree of vulnerability and seismic risk of Metropolitan Lima and Callao. The large seismic event that could occur in Metropolitan Lima and Callao would be of $8 \mathrm{Mw}$ magnitude with a maximum intensity of VIII on the modified Mercalli scale. It would have an epicenter in front of Lima with a depth of 33 kilometers, which could trigger a tsunami with waves of 6 meters high and 200 kilometers wide, at a speed of $400 \mathrm{~km} / \mathrm{h}$.

The district of San Borja has an area of 9.96 square kilometers with a population of 111,928 inhabitants and 28,269 homes [11] [12] [13]. On the other hand, the district of San Luis has an area of 3.49 square kilometers with a population of 57,600 inhabitants and 13,347 homes [11] [12] [13]. Making an intersection with the reference study [10], there are an estimated 3357 victims in San Borja and 1269 victims in San Luis.

\section{B. Methodology}

Humanitarian goods are stored in warehouses nationwide. The hierarchy that is handled is as follows: the national warehouses supply the regional warehouses, they supply the advanced warehouses and, finally, from the advance warehouses the aid is distributed to the victims [3]. There are a total of 12 national warehouses, 25 regional warehouses and 138 advanced warehouses. Figure 1 shows the distribution of the advanced warehouses in Peru.

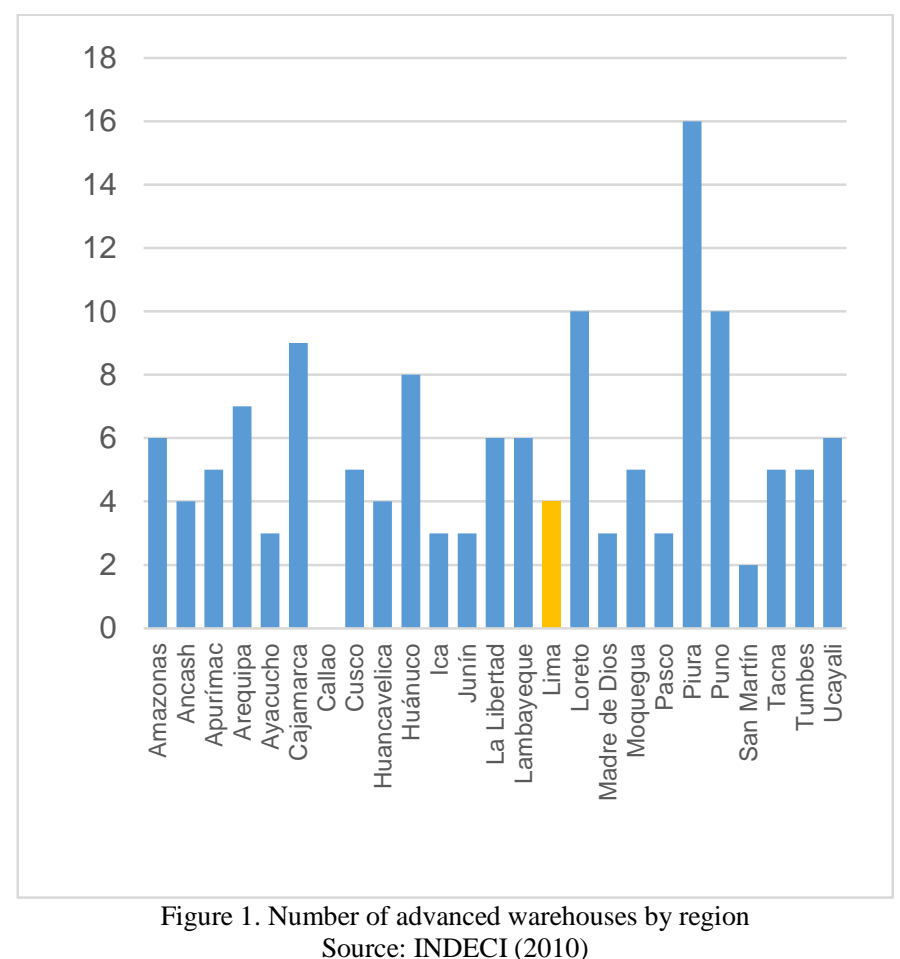

In the case of Lima, there are 4 advanced warehouses located in: Chosica, Matucana, Atioquía and Huacho [3]. These stores would be in charge of distributing the necessary help to the affected population, which would be quite complicated if the entire population of Metropolitan Lima is targeted. For this reason, it would be more convenient for the aid to be distributed to clusters as municipalities and that these be responsible for distributing it.

For this analysis, the districts of San Borja and San Luis have been taken as a cluster because of their similarities in soil and building quality, as well as their geographical proximity. This cluster would have an approximate demand of 4,626 victims who would be offered free of charge humanitarian goods. However, visiting one by one is a very complicated task and will probably take a long time.

For this reason, it is recommended to distribute the aid in some common area and people come to these places to receive help. To facilitate the management of spaces, it is suggested that it be in green and wide areas such as parks. Figure 2 illustrates an example with four parks that would serve as a meeting point for the population to receive humanitarian aid goods.

16 $^{\text {th }}$ LACCEI International Multi-Conference for Engineering, Education, and Technology: "Innovation in Education and Inclusion", 19-21 July 2018, Lima, Peru. 
The main parks of these two districts were located to be considered as demand nodes for the model. As an initial scheme, the goods would reach a strategic point in this cluster and then be distributed to the aforementioned nodes. In figure 3 , all the nodes identified in the aforementioned cluster are illustrated.

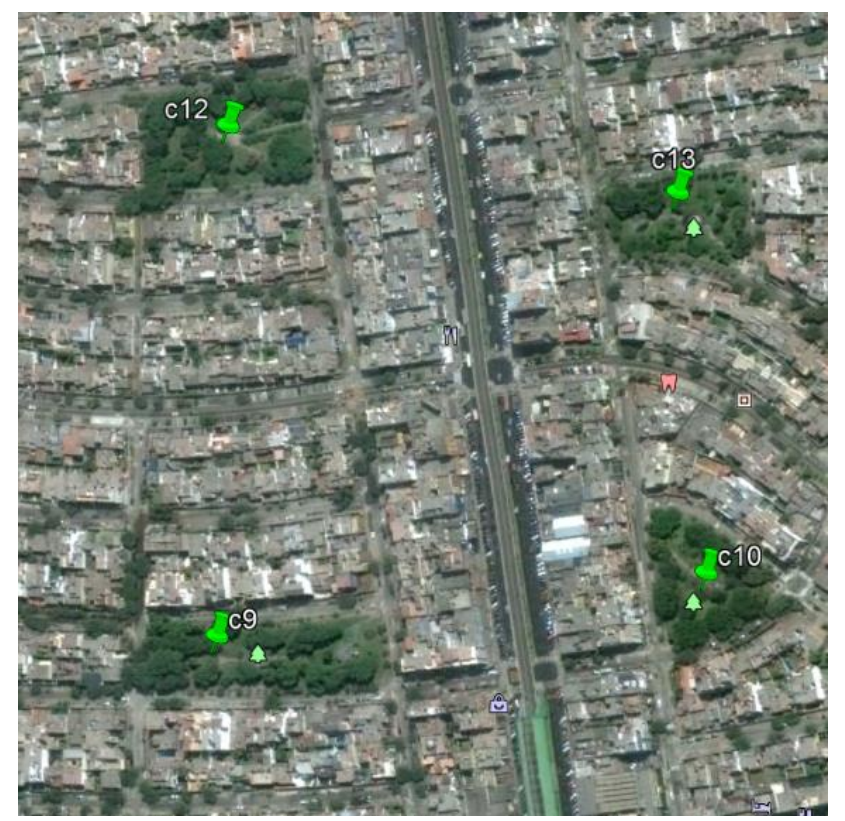

Figure 2. Example of nodes located in parks Source: Google Earth

Even limiting coverage to the San Borja and San Luis cluster could be very difficult to distribute all the necessary help within an acceptable time. One strategy that is suggested is to divide this cluster into groups by proximity and activate temporary stores for each group and thus expedite the distribution. The advantage of defining the temporary storage after the earthquake is that there is more certainty of the demand, unlike having constructed it a priori.

Then, the strategy would be to conduct a quick census just after the earthquake of great magnitude to get an idea of the quantity demanded of humanitarian aid goods. Then, determine how many temporary warehouses would be ideal to implement, and then move on to the actual distribution to the affected population. The number of temporary warehouses will depend directly on the total quantity demanded and the volume of what is thought to be distributed.

For the first phase it is recommended to use the method of the $\mathrm{k}$ mean in $\mathrm{R}$, because the district has the flexibility to implement the temporary warehouse even in the street. On the other hand, it would be necessary to evaluate if the distribution is more adjusted to a general vehicle routing problem model, or to the specific case of the traveling agent problem. This stage could be executed in some optimized as it is the AMPL program.

Next, a case in which you want to implement 3 temporary stores will be carried out as an example. Each of the nodes was located on the map using the Google Earth program and the file in $\mathrm{kmz}$ format was processed in the Global Mapper program. Table 1 shows the coordinates already converted to UTM with the help of this second program. The advantage of working with these units is that they treat the map as a Cartesian plane where $\mathrm{X}, \mathrm{Y}$ coordinates are located, unlike the latitudes and longitudes that drive units of degrees.

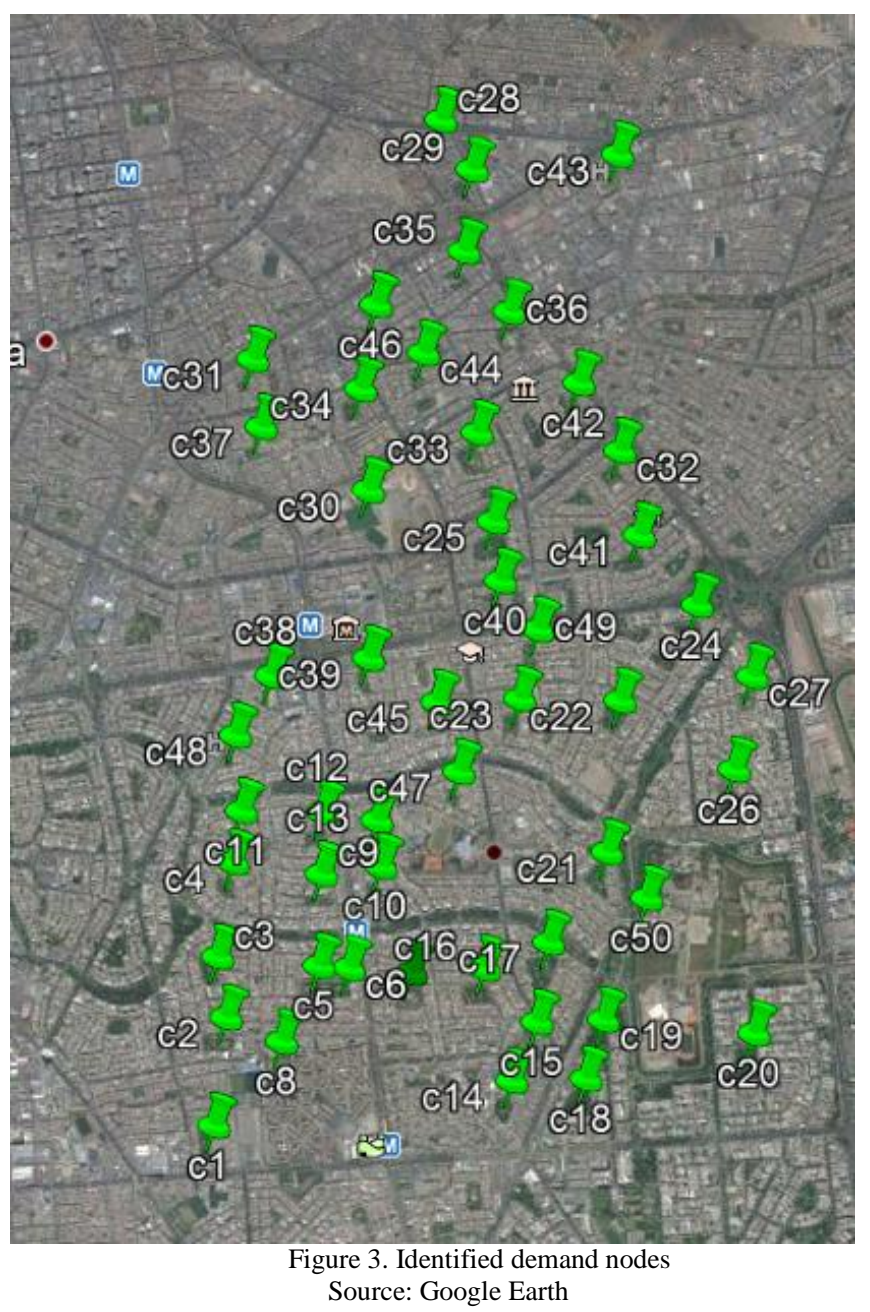

Another important parameter to be able to solve this example is the matrix of distances between each pair of nodes. To do this, the Pythagorean formula is applied to finish the distance between each pair of nodes, obtaining a result in meters since the units are in UTM coordinates. However, this distance is linear from one point to another which does not adequately reflect reality. To adjust this, multiply the linear distance by the root of two, assuming that the vehicle will move through the legs and not by the hypotenuse that would represent the direct path without considering the limitations of streets.

\section{Location example}

As mentioned in the previous point, the average $\mathrm{k}$ method will be used to determine the location of the stores. For this 
punctual example, a $\mathrm{k}$ equal to 4 stores will be used, the result of which will be shown in figure 4 .

Table 1. Nodes in UTM coordinates

\begin{tabular}{|c|c|c|}
\hline Nodo & $\mathbf{X}$ & $\mathbf{Y}$ \\
\hline $\mathrm{c} 1$ & 281,582 & $8,660,706$ \\
\hline $\mathrm{c} 2$ & 281,648 & $8,661,266$ \\
\hline $\mathrm{c} 3$ & 281,605 & $8,661,578$ \\
\hline $\mathrm{c} 4$ & 281,686 & $8,662,068$ \\
\hline $\mathrm{c} 5$ & 282,132 & $8,661,535$ \\
\hline $\mathrm{c} 6$ & 282,287 & $8,661,524$ \\
\hline $\mathrm{c} 7$ & 282,610 & $8,661,502$ \\
\hline $\mathrm{c} 8$ & 281,937 & $8,661,144$ \\
\hline c9 & 282,145 & $8,662,008$ \\
\hline $\mathrm{c} 10$ & 282,453 & $8,662,050$ \\
\hline c11 & 281,731 & $8,662,331$ \\
\hline $\mathrm{c} 12$ & 282,152 & $8,662,326$ \\
\hline c13 & 282,434 & $8,662,286$ \\
\hline $\mathrm{c} 14$ & 283,133 & $8,660,947$ \\
\hline $\mathrm{c} 15$ & 283,263 & $8,661,251$ \\
\hline $\mathrm{c} 16$ & 282,991 & $8,661,528$ \\
\hline $\mathrm{c} 17$ & 283,324 & $8,661,662$ \\
\hline c18 & 283,517 & $8,660,960$ \\
\hline c19 & 283,609 & $8,661,265$ \\
\hline $\mathrm{c} 20$ & 284,389 & $8,661,199$ \\
\hline c21 & 283,627 & $8,662,128$ \\
\hline $\mathrm{c} 22$ & 283,693 & $8,662,907$ \\
\hline $\mathrm{c} 23$ & 283,175 & $8,662,914$ \\
\hline c24 & 284,092 & $8,663,398$ \\
\hline $\mathrm{c} 25$ & 283,037 & $8,663,823$ \\
\hline c26 & 284,285 & $8,662,555$ \\
\hline $\mathrm{c} 27$ & 284,376 & $8,663,033$ \\
\hline $\mathrm{c} 28$ & 282,765 & $8,665,878$ \\
\hline c29 & 282,927 & $8,665,625$ \\
\hline c30 & 282,390 & $8,663,981$ \\
\hline c31 & 281,791 & $8,664,651$ \\
\hline c32 & 283,692 & $8,664,186$ \\
\hline c33 & 282,954 & $8,664,277$ \\
\hline c34 & 282,351 & $8,664,501$ \\
\hline c35 & 282,886 & $8,665,206$ \\
\hline $\mathrm{c} 36$ & 283,120 & $8,664,897$ \\
\hline c37 & 281,834 & $8,664,306$ \\
\hline c38 & 281,885 & $8,663,027$ \\
\hline c39 & 282,392 & $8,663,119$ \\
\hline $\mathrm{c} 40$ & 283,075 & $8,663,519$ \\
\hline $\mathrm{c} 41$ & 283,793 & $8,663,755$ \\
\hline $\mathrm{c} 42$ & 283,480 & $8,664,533$ \\
\hline $\mathrm{c} 43$ & 283,679 & $8,665,700$ \\
\hline $\mathrm{c} 44$ & 282,676 & $8,664,685$ \\
\hline $\mathrm{c} 45$ & 282,748 & $8,662,893$ \\
\hline $\mathrm{c} 46$ & 282,431 & $8,664,932$ \\
\hline $\mathrm{c} 47$ & 282,860 & $8,662,538$ \\
\hline $\mathrm{c} 48$ & 281,699 & $8,662,720$ \\
\hline $\mathrm{c} 49$ & 283,268 & $8,663,270$ \\
\hline $\mathrm{c} 50$ & 283,833 & $8,661,892$ \\
\hline
\end{tabular}

In this chart, four groups have been made, since $\mathrm{k}$ was predefined in the model as four, each of a different color: blue, red, black and green. The center of gravity of each group is the large cyan spot. The nodes in each group are the following:

Black

c1, c2, c5, c6, c7, c8, c14, c15, c16, c17, c18, c19, c20.

Red

c21, c22, c23, c24, c26, c27, c40, c41, c49, c50.

Blue

c3, c4, c9, c10, c11, c12, c13, c38, c39, c45, c47, c48

Green

c25, c28, c29, c30, c31, c32, c33, c34, c35, c36, c37, c42, c43, c44, c46.

In the black group there are 13 assigned nodes, in the red group there are 10 nodes, in the blue group there are 12 nodes, and in the green group there are 15 nodes. The depot of each group should be located where the cyan dots are located.

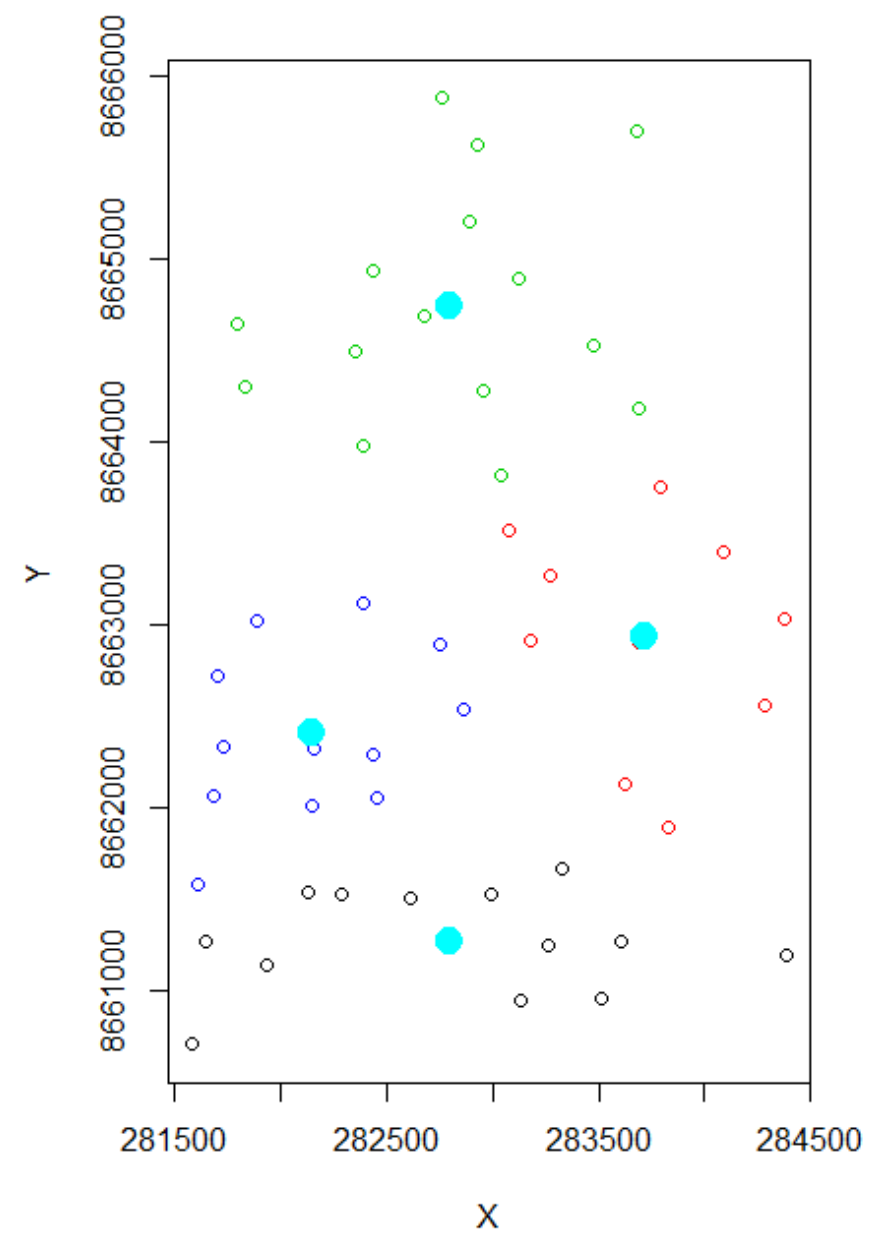

Figure 4. K mean clustering

\section{Routing example}

With the information obtained in the previous point, the routing will be performed for each of the 4 groups. The parameter that varies is the distance matrix in each of the groups and the 
extension of it. The most critical warehouse in terms of nodes to visit has 15 points of demand. This amount can still be supported by optimization software.

For this example, the AMPL optimization software was used in its student version using the solver CPLEX version 12.6.3.0. A core i5 laptop with $8 \mathrm{~GB}$ of RAM was used.

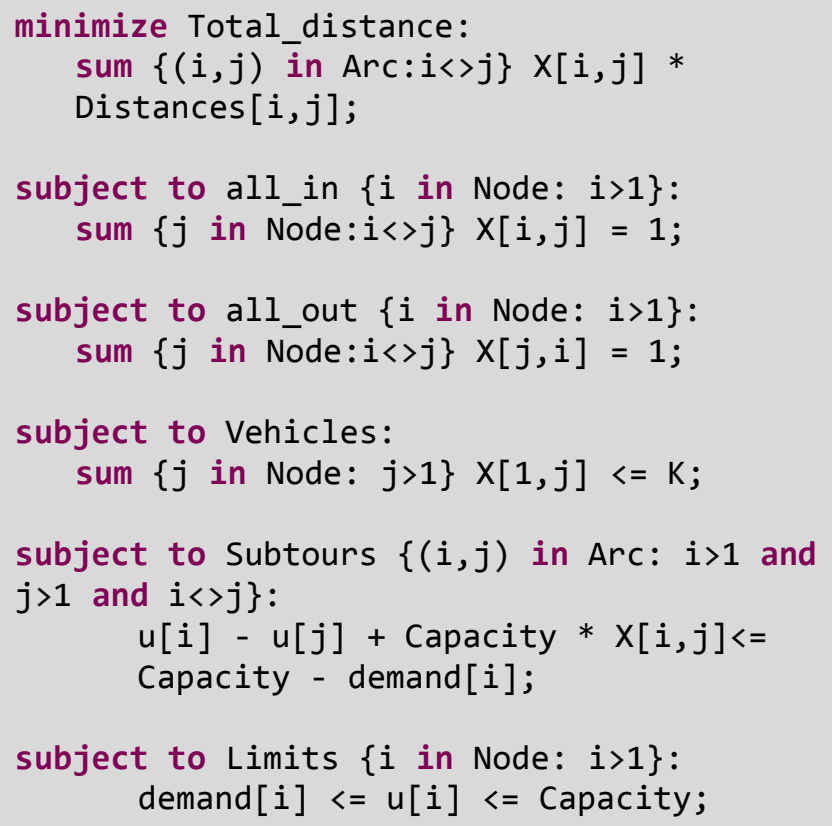

\section{RESULTS}

\section{A. Travel distance} results:

After solving each group separately, we have the following

Black

9.995 kilometers

Depot - c8-c1-c2 - c5-c6-c7-c16-c17-c15-c19

- c20-c18-c14-Depot

Red

7.551 kilometers

Depot - c22 - c21 - c50 - c26 - c27 - c24 - c41 - c40 c49-c23 - Depot

Blue

7.212 kilometers

Depot - c12-c9-c3-c4-c11-c48- c38-c39-c45

- c47-c10-c13- Depot

Green

11.782 kilometers

Depot - c44 - c46 - c34 - c31 - c37 - c30 - c33 - c25 c32-c42-c43-c28-c29-c35-c36 - Depot

In figure 5 we can see graphically how these 4 proposed routes would be. In total, 36.54 kilometers are traveled in order to deliver humanitarian aid goods to the affected population.

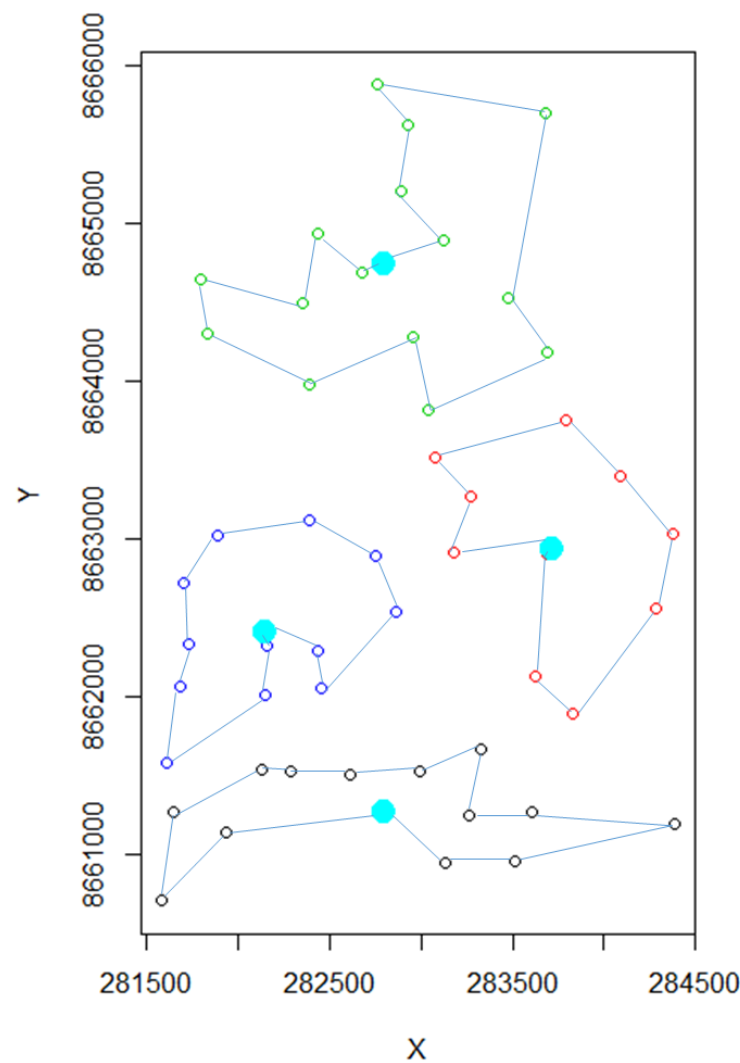

Figure 5. Optimal routes for each group

When these four temporary warehouses are supplied, it should take approximately 1 hour to distribute all the humanitarian aid goods. Even several types of goods could be distributed as those of the non-food category that has greater variety.

\section{CONCLUSION}

The proposed methodology was applied to a Lima cluster formed by the districts of San Borja and San Luis, obtaining 4 temporary warehouses that served 13, 10, 12 and 15 demand nodes, respectively.

For this example, the warehouse with the most points to visit was the green that served north of the cluster. However, having 15 demand nodes was still feasible to be solved by optimization software or by programs such as Graphs. If the load is greater, the use of heuristics is recommended, such as the saving algorithm [14] or the two-phase algorithm of assigning first and then routing [15]. And, if the load is greater, an additional temporary warehouse would be evaluated.

\section{REFERENCES}

[1] United States Geological Survey, data base, 2017.

[2] J. Kuroiwa, "Reducción de desastres: viviendo en armonía con la naturaleza", Programa de Naciones Unidas para el Desarrollo, 2002.

[3] Instituto Nacional De Defensa Civil, "Compendio estadístico de prevención y atención de desastres", 2010.

[4] IACOB, S. V. (2014). Distribution center optimum localization and the gravitational model. Journal of Applied Quantitative Methods, 62.

[5] Zhao, Y. (2012). R and data mining: Examples and case studies. Academic Press. 
[6] P. Toth y D. Vigo, "The vehicle routing problem", SIAM Monographs on Discrete Mathematics and Applications, 2002.

[7] G. Dantzig y J. Ramser, "The truck dispatching problem", Management science, 6(1), 80-91, 1959.

[8] P. Toth y D. Vigo, "Vehicle routing: problems, methods and applications", SIAM Monographs on Discrete Mathematics and Applications, 2014.

[9] C. Miller, A. Tucker y R. Zemlin, "Integer programming formulation of traveling salesman problems", Journal of the ACM (JACM), 7(4), 326-329, 1960.

[10]PREDES, "Diseño de escenario sobre el impacto de un sismo de gran magnitud en Lima Metropolitana y Callao", Lima, Perú, 2009.

[11]Instituto Nacional de Estadística e Informática, "Lima Metropolitana Perfil Socio-Demográfico", Lima, Perú, 1996.

[12]Instituto Nacional de Estadística e Informática, "Estimaciones y Proyecciones de Población”, Lima, Perú, 2015.

[13]Instituto Nacional de Estadística e Informática, "Censos Nacionales 2007: XI de Población y VI de Vivienda", Lima, Perú, 2007.

[14]G. Clarke y J. Wright, "Scheduling of vehicles from a central depot to a number of delivery points", Operations research, 12(4), 568-581, 1964.

[15] B. Gillett y L. Miller, "A heuristic algorithm for the vehicle-dispatch problem”, Operations research, 22(2), 340-349, 1974.

16 $^{\text {th }}$ LACCEI International Multi-Conference for Engineering, Education, and Technology: "Innovation in Education and Inclusion", 19-21 July 2018, Lima, Peru. 